\title{
Gerenciamento de resíduos sólidos no serviço de saúde
}

\section{Jordana Marques Kneipp}

Bacharel em Administração pela Universidade Federal de Pelotas (UFPel) e Mestranda em Administração pela Universidade Federal de Santa Maria (UFSM)

jordanakneipp@yahoo.com.br

\section{Thiago Antonio Beuron}

Bacharel em Administração pela Universidade Estadual do Centro Oeste (UNICENTRO). Mestrando em Administração pela Universidade Federal de Santa Maria (UFSM)

tbeuron@gmail.com

\section{Aletéia de Moura Carpes}

Bacharel em Administração- habilitação em Comércio Exterior pela Faculdade metodista de Santa Maria (FAMES) e Mestranda em Administração na Universidade Federal de Santa Maria

alecarpes.adm@hotmail.com

\section{Ana Paula Perlin}

Acadêmica do Curso de Bacharelado em Administração da Universidade Federal de Santa Maria (UFSM) anapaula.perlin@yahoo.com.br

\section{Clandia Maffini Gomes}

Doutora em Administração pela Universidade de São Paulo. Atualmente é Professora Adjunta do Departamento de Ciências Administrativas da Universidade Federal de Santa Maria.

clandia@smail.ufsm.br

RESUMO: A manipulação inadequada de resíduos de serviços de saúde (RSS) pode representar grandes riscos e problemas ao meio ambiente e à saúde humana. Os RSS são aqueles provenientes de todos os estabelecimentos prestadores de serviços de saúde e, desta forma, este estudo possui como objetivo analisar o gerenciamento dos RSS em um hospital universitário, localizado no estado do Rio Grande do Sul. A pesquisa caracteriza-se como qualitativa, exploratória, e adota como método o estudo de caso. A coleta de dados foi realizada por meio de observação direta e entrevista semi-estruturada com o responsável técnico pelo gerenciamento de resíduos do hospital analisado. Os resultados evidenciaram a significativa preocupação do hospital com o gerenciamento adequado dos RSS, em que se destaca, desde 2003, a implantação do Plano de Gerenciamento de Resíduos do Serviço de Saúde, o qual normatiza e descreve as etapas de segregação, manejo e descarte dos resíduos hospitalares, a fim de que os riscos oferecidos sejam minimizados. Ressalta-se a importância da preocupação ambiental por parte das organizações de saúde, tendo em vista que ao prestarem assistência para a população, torna-se imprescindível a segurança nos serviços prestados, já que qualquer ação indevida pode acarretar danos para os pacientes, profissionais da área da saúde e comunidade em geral.

PALAVRAS-CHAVE: Gerenciamento. Resíduos. Saúde.

\section{SOLID WASTE MANAGEMENT IN THE HEALTH SERVICE}

ABSTRACT: The improper handling of waste from health services (RSS) can pose great risks and problems to the environment and human health. The RSS are those from all establishments providing health care and this study aims to analyze the management of RSS in a university hospital, located in the state of Rio Grande do Sul. The research is characterized as qualitative, exploratory, and adopts as method, the case study. Data collection was conducted through direct observation and semi-structured interview with the technician responsible for the management of hospital residues analyzed. The results highlighted the significant concern of the hospital with the proper management of the RSS, especially the implementation in 2003 of the Waste Management Plan of the Health Service - PGRSS, which standardizes and describes the stages of segregation, handling and disposal of hospital waste, in order to minimize risks. Thus, the study highlights the importance of environmental concern on the part of health organizations in order to provide assistance to the population, it is essential to the security services, since any action may cause undue harm to patients, health professionals and community.

KEYWORDS: Management. Waste. Health. 


\section{INTRODUÇÃO}

O gerenciamento de resíduos de serviços de saúde (RSS) é considerado um assunto polêmico e amplamente discutido, ao considerar que a manipulação inadequada deste tipo de resíduo pode representar grandes riscos e problemas ao meio ambiente e à saúde humana.

Os impactos ambientais ocasionados pelo gerenciamento inadequado dos resíduos hospitalares podem acarretar graves conseqüências para o meio ambiente e para a população, desde contaminações e elevados índices de infecção hospitalar até a geração de epidemias e endemias (NAIME, RAMALHO E NAIME, 2008).

A NBR 12807 da ABNT (1993) define resíduos de serviços de saúde como os resíduos resultantes das atividades exercidas por estabelecimentos prestadores de serviços de saúde. Corroborando, Coelho (2001) ressalta que os RSS são aqueles gerados por prestadores de assistência médica, odontológica, laboratorial, farmacêutica e instituições de ensino e pesquisa médica, relacionados tanto à população humana quanto à veterinária. Segundo o autor, estes resíduos possuem potencial de risco, em função da presença de materiais biológicos capazes de causar infecção, objetos perfurantes-cortantes potenciais, ou efetivamente contaminados, produtos químicos perigosos. Até mesmo, rejeitos radioativos requerem cuidados específicos de acondicionamento, transporte, armazenamento, coleta, tratamento e disposição final.

Com relação aos resíduos dos serviços de saúde, somente nos últimos anos iniciou-se uma discussão mais consistente no que se refere a esta problemática, sendo que algumas prefeituras já implantaram sistemas específicos para a coleta dos mesmos. No entanto, ainda não existe uma preocupação maior com a manipulação correta dos RSS dentro dos estabelecimentos de saúde, de forma que sejam separados os resíduos com real potencial de contaminação, daqueles que são considerados lixo comum. A forma adequada de destinação final ainda não é consenso entre as organizações de saúde, e muitos municípios dispõem esses resíduos em lixões, sendo estes, alvos de disputa entre os catadores, tendo em vista o percentual atrativo de materiais recicláveis dos mesmos. (MONTEIRO et. al., 2001).

Neste sentido, a fim de ampliar a discussão no que se refere a esta temática, este estudo tem por objetivo central a análise do gerenciamento dos RSS em um hospital universitário, localizado no interior do estado do Rio Grande do Sul.

O texto foi organizado em seis seções, sendo a primeira a introdução. A segunda oferece uma contextualização sobre resíduos sólidos urbanos, a terceira trata especificamente dos resíduos de serviços de saúde, o próximo item evidencia o método utilizado para o desenvolvimento do presente estudo. A quinta seção apresenta a análise dos dados e discussão dos resultados. Por fim, a última seção recupera alguns aspectos analisados de modo evidenciar as contribuições do trabalho.

\section{RESÍDUOS SÓLIDOS URBANOS}

O desenvolvimento econômico e tecnológico ocasionou reflexos para sociedade e para o meio ambiente, acarretando em muitas mudanças sociais, econômicas e também ambientais. Com relação ao contexto ambiental, existe uma ampla discussão em todos os âmbitos da sociedade, em decorrência dos diversos problemas que assolam o mundo atual, tais como: aquecimento global, desmatamento, problemas de saneamento básico, qualidade do ar, geração excessiva de resíduos, entre tantos outros que afetam e ameaçam a vida terrestre.

A geração de resíduos é um problema que vem se agravando gradativamente, tendo em vista que, com o passar do tempo, ocorreu um considerável aumento na produção de lixo, o que está diretamente relacionado aos hábitos de vida da população, bem como as tecnologias aplicadas na produção de bens de consumo.

De acordo com a Norma Brasileira Regulamentadora - NBR 10004, da Associação Brasileira de Normas Técnicas - ABNT (2004), resíduos sólidos são todos os resíduos nos estados sólido e semi-sólido, os quais resultam de atividades de origem industrial, doméstica, hospitalar, comercial, agrícola, de serviços e de varrição. Considera-se também resíduo sólido, os lodos provenientes de sistemas de tratamento de água, aqueles gerados em equipamentos e instalações de controle de poluição, bem como determinados líquidos cujas particularidades tornem inviável o seu lançamento na rede pública de esgotos ou corpos de água, ou exijam, para isso, soluções técnicas e economicamente inviáveis tendo em vista a melhor tecnologia disponível.

Na visão de Almeida e Amaral (2006), as facilidades criadas para atender demandas de uma sociedade consumista geram uma excessiva produção de lixo urbano, o que consiste em um dos maiores problemas sanitários e ambientais, enfrentado, principalmente, pelos países menos desenvolvidos. Ressaltam ainda que, muitas vezes, não são considerados os cuidados necessários para a eliminação destes resíduos, sendo 
imprescindíveis melhorias no gerenciamento dos mesmos, bem como maior conscientização ambiental, a fim de que se reduza a geração de lixo urbano e se promova seu tratamento adequado.

O gerenciamento adequado dos resíduos sólidos urbanos consiste em um grande desafio da sociedade atual, visto que a produção de lixo é cada vez maior e as ações para o seu tratamento e disposição final ainda são bastante deficitárias.

Este estudo tratará especificamente dos RSS, já que a complexidade que envolve o gerenciamento destes resíduos está relacionada a uma ampla gama de atividades, e também em decorrência das graves conseqüências que podem ser geradas a partir da manipulação inadequada destes resíduos, o que acarreta em grandes riscos e problemas ao meio ambiente e à saúde humana.

\section{RESÍDUOS DE SERVIÇOS DE SAÚDE (RSS)}

A NBR 12807 da ABNT (1993) define RSS como aqueles resultantes das atividades exercidas por estabelecimentos prestadores de serviços de saúde.

De acordo com Coelho (2001) os RSS são aqueles gerados por prestadores de assistência médica, odontológica, laboratorial, farmacêutica e instituições de ensino e pesquisa médica, relacionados tanto à população humana quanto à veterinária. Segundo o autor estes resíduos requerem cuidados específicos de acondicionamento, transporte, armazenamento, coleta, tratamento e disposição final, quando possuem potencial de risco, em função da presença de materiais biológicos capazes de causar infecção, objetos perfuro-cortantes potencial ou efetivamente contaminados, produtos químicos perigosos, e mesmo rejeitos radioativos.

Corroborando, Cussiol (2008) coloca que os RSS são aqueles resultantes de atividades executadas por estabelecimento gerador que, de acordo com as características de cada tipo de resíduo, necessitam de processos diferenciados no manejo, exigindo ou não-tratamento prévio para a disposição final.

A existência de resíduos provenientes da prestação de serviços de saúde a seres vivos (humanos ou animais), incluindo as atividades médicas de prevenção, diagnóstico, tratamento e análise, constitui-se em uma preocupação a fim de prevenir possíveis impactos que possam afetar a população e o meio ambiente (CARRAMENHA, 2005).

Nesse contexto, para Oliveira (2002), a atividade hospitalar consiste em uma grande geradora de resíduos. Para o mesmo autor, os RSS sempre representaram problemas consideravelmente sérios para os administradores hospitalares, devido, principalmente, à falta de informações, que produzem mitos e fantasias entre funcionários, pacientes, familiares e nas comunidades vizinhas aos hospitais e aos locais de disposição final.

Segundo Cussiol (2008, p.9) "o gerenciamento correto dos resíduos gerados em estabelecimentos prestadores de serviços de saúde é importante para garantir a qualidade da saúde coletiva e a preservação do meio ambiente".

O mesmo autor coloca que o gerenciamento de resíduos compreende o conjunto de atividades técnicas e administrativas relacionadas ao manuseio, à minimização da geração, à segregação na origem, à coleta, ao acondicionamento, ao transporte, ao armazenamento, ao tratamento, ao controle, ao registro e à disposição final dos resíduos.

Para Moura e Viriato (2008), o objetivo fundamental do gerenciamento dos resíduos sólidos é minimizar os riscos à saúde da população interna e externa do estabelecimento de saúde. Estes autores ainda afirmam que devido à enorme diversidade de estabelecimentos relacionados a área da saúde, torna-se praticamente impossivel estabelecer parâmetros quanto à geração de RSS.

Segundo a Organização Pan-americana de Saúde (1997), o gerenciamento adequado dos resíduos sólidos não implica somente em controlar e diminuir os riscos, mas também alcançar a redução dos resíduos desde o ponto de origem, o que elevaria também a qualidade e a eficiência dos serviços dos estabelecimentos de saúde.

Um sistema adequado de manejo dos resíduos sólidos em um estabelecimento de saúde permite o controle e a redução com segurança e economia dos riscos para a saúde e, também, a minimização dos impactos ambientais gerados.

Os instrumentos legais que merecem destaque com relação ao tema são: a Resolução da Diretoria Colegiada - RDC da Agência Nacional de Vigilância Sanitária - ANVISA n 306/2004, que dispõe sobre o Regulamento Técnico para o gerenciamento de resíduos de serviços de saúde; e a Resolução do Conselho 
Nacional de Meio Ambiente - CONAMA n⿳ $358 / 2005$, que dispõe sobre o tratamento e a disposição final dos resíduos dos serviços de saúde e dá outras providências (CUSSIOL, 2008).

De acordo com a Resolução $n^{\circ} .358$ do CONAMA (2005), os resíduos da área de saúde são agrupados da seguinte forma:

- GRUPO A: Resíduos com a possível presença de agentes biológicos que, por suas características de maior virulência ou concentração, podem apresentar risco de infecção. Esse grupo divide-se em A1 (descarte de vacinas de microorganismos, bolsas transfusionais, resíduos laboratoriais), A2 (resíduos provenientes de animais), A3 (peças anatômicas de ser humano), A4 (filtros de ar e gases aspirados de área contaminada, resíduos de tecido adiposo), A5 (Materiais perfuro cortantes provenientes de seres contaminados com príons);

- GRUPO B: Resíduos que contenham substâncias químicas que podem apresentar risco à saúde pública ou ao meio ambiente, dependendo de suas características de inflamabilidade, corrosividade, reatividade e toxicidade. Nesse grupo, encontram-se os produtos hormonais, produtos antimicrobianos, imunomoduladores, resíduos e insumos farmacêuticos dos medicamentos controlados, resíduos de saneantes, desinfetantes, resíduos contendo metais pesados; reagentes para laboratório, inclusive os recipientes contaminados por estes;

- GRUPO C: Todo material resultante de atividades humanas que contenham radionuclídeos em quantidades superiores aos limites de eliminação especificados nas normas da Comissão Nacional de Energia Nuclear - CNEN e para os quais a reutilização é imprópria ou não prevista. Fazem parte desse grupo quaisquer materiais resultantes de laboratórios de análises clínicas, nuclear e radioterapia que contenham radionuclídeos em quantidade superior aos limites de eliminação;

- GRUPO D: Resíduos que não apresentem risco biológico, químico ou radiológico à saúde ou ao meio ambiente, podendo ser equiparados aos resíduos domiciliares. Enquadram-se nesse grupo, papel de uso sanitário e fralda, resto alimentar de paciente, material utilizado em anti-sepsia, equipo de soro, resíduos provenientes das áreas administrativas, resíduos de varrição, jardins, resíduos de gesso provenientes de assistência à saúde;

- GRUPO E: Resíduos perfurocortantes ou escarificantes, tais como: lâminas de barbear, agulhas, escalpes, ampolas de vidro, limas endodônticas, lâminas de bisturi, lancetas; tubos capilares, micropipetas; lâminas e lamínulas, espátulas, e os utensílios de vidro quebrados no laboratório.

A resolução do CONAMA $n^{\circ} 358$ (2005) ressalta que é responsabilidade dos estabelecimentos prestadores de serviços de saúde o gerenciamento dos resíduos, desde a geração até a disposição final, de forma a atender aos requisitos ambientais e de saúde pública e saúde ocupacional, sem prejuízo de responsabilização solidária de todos aqueles, pessoas físicas e jurídicas que, direta ou indiretamente, causem ou possam causar degradação ambiental, em especial os transportadores e operadores das instalações de tratamento e disposição final.

Torna-se necessário que o estabelecimento de saúde proporcione o manuseio seguro dos resíduos, uma vez que essa operação envolve risco potencial de acidente, principalmente para os profissionais que atuam diretamente nas etapas de gerenciamento (CUSSIOL, 2008). A NBR 12810 da ABNT (1993) ressalta que os Equipamentos de Proteção Individual - EPI devem ser os mais adequados para lidarem com resíduos de serviços de saúde, colocando que o uniforme deve ser composto por calça comprida e camisa com manga, no mínimo de $3 / 4$, de tecido resistente e de cor clara, específico para o uso do funcionário do serviço, de forma a identificá-lo de acordo com a sua função, devem ainda utilizar luvas, botas, gorro, máscara, óculos e avental.

Segundo as Resoluções RDC 306/2004 da ANVISA e 358/2005 do CONAMA, todo o gerador de RSS deve elaborar um Plano de Gerenciamento de Resíduos de Serviços de Saúde - PGRSS, baseado nas características dos resíduos gerados e na classificação existente, estabelecendo as diretrizes de manejo dos RSS. O PGRSS deve ser compatível com as normas locais relativas à coleta, transporte e disposição final dos resíduos gerados nos serviços de saúde, estabelecidas pelos órgãos locais responsáveis por estas etapas.

A RDC da ANVISA n 306 (2004) entende como manejo dos RSS, a ação de gerenciar os resíduos em seus aspectos intra e extra estabelecimento, desde a geração até a disposição final, incluindo as etapas de: segregação, acondicionamento, identificação, transporte interno, armazenamento temporário, tratamento, armazenamento externo, coleta e transporte externos e disposição final. Dessa forma, a seguir será apresentada cada uma destas etapas relacionadas ao gerenciamento dos RSS. 


\subsection{Segregação}

De acordo com a RDC da ANVISA n ${ }^{\circ}$. 306/2004, a etapa de segregação consiste na separação dos resíduos no momento e local de sua geração, de acordo com as características físicas, químicas, biológicas, o seu estado físico e os riscos envolvidos.

Segundo a Organização Pan-americana (1997) de Saúde, a segregação é uma das operações fundamentais para permitir o cumprimento dos objetivos de um sistema eficiente de manuseio de resíduos e consiste em separar ou selecionar apropriadamente os resíduos segundo a classificação adotada. Essa operação deve ser realizada na fonte de geração, condicionada à prévia capacitação do pessoal de serviço.

Para Monteiro et. al. (2001), o procedimento mais importante no manuseio de resíduos de serviços de saúde consiste na separação na origem do lixo infectante dos resíduos comuns, uma vez que o primeiro representa apenas de 10 a 15\% do total de resíduos, e o lixo comum não necessita de maiores cuidados.

\subsection{Acondicionamento}

Esta etapa consiste no ato de embalar os resíduos segregados em sacos ou recipientes que evitem vazamentos e resistam às ações de punctura e ruptura. A capacidade dos recipientes de acondicionamento deve ser compatível com a geração diária de cada tipo de resíduo (RDC ANVISA n. 306, 2004).

O acondicionamento dos resíduos na origem consiste em controlar os riscos para a saúde e facilitar as operações de coleta, armazenamento externo e transporte, sem prejudicar o desenvolvimento natural das atividades do estabelecimento. Os recipientes utilizados necessitam ser apropriados para cada tipo de resíduo, sendo que o tamanho, o peso, a cor, a forma e o material devem garantir uma apropriada identificação, facilitar as operações de transporte e limpeza, ser herméticos para evitar exposições desnecessárias e estar integrados às condições físicas e arquitetônicas do local. Esses recipientes são complementados com o uso de sacos plásticos para efetuar uma embalagem apropriada dos resíduos (ORGANIZAÇÃO PAN-AMERICANA DE SAÚDE, 1997).

De acordo com a RDC ANVISA nº 306 (2004), os resíduos sólidos devem ser acondicionados em saco constituído de material resistente à ruptura e vazamento, impermeável, respeitados os limites de peso de cada saco, sendo proibido o seu esvaziamento ou reaproveitamento.

\subsection{Identificação}

Segundo a RDC da ANVISA n. 306/2004, o processo de identificação constitui-se no conjunto de medidas que permite o reconhecimento dos resíduos contidos nos sacos e recipientes, fornecendo informações ao correto manejo dos RSS. A identificação deve constar nos sacos de acondicionamento, nos recipientes de coleta interna e externa, nos recipientes de transporte interno e externo e nos locais de armazenamento,

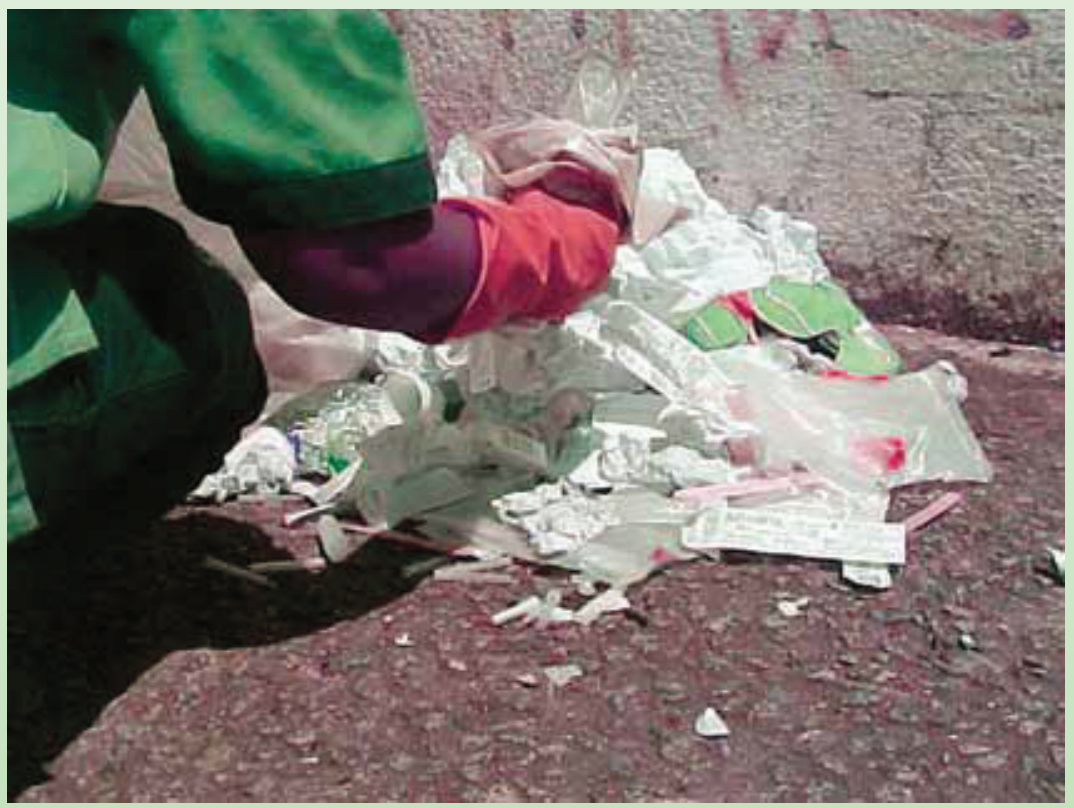


em local de fácil visualização, em que se utilizem símbolos, cores e frases, atendendo aos parâmetros referenciados na norma NBR 7500 da ABNT, além de outras exigências relacionadas à identificação de conteúdo e ao risco específico de cada grupo de resíduos.

\subsection{Transporte interno}

Consiste no traslado dos resíduos dos pontos de geração até local destinado ao armazenamento temporário ou armazenamento externo com a finalidade de apresentação para a coleta. $\mathrm{O}$ transporte interno de resíduos no estabelecimento deve ser realizado de acordo com um roteiro previamente definido e em horários não coincidentes com a distribuição de roupas, alimentos e medicamentos, períodos de visita ou de maior fluxo de pessoas e atividades. O transporte deve ser feito separadamente, isto é, em recipientes específicos para cada grupo de resíduos (RDC ANVISA nº. 306, 2004).

Complementando Cussiol (2008), coloca que o carro ou recipiente utilizado para o transporte interno dos resíduos deve ser de uso exclusivo e específico para cada grupo de resíduo, sendo constituído de material rígido, lavável, impermeável, provido de tampa articulada ao próprio corpo do equipamento, com cantos e bordas arredondados e identificados com o símbolo correspondente ao risco do resíduo que transportará.

\subsection{Armazenamento temporário}

De acordo com a RDC da ANVISA nº 306 (2004), o armazenamento temporário corresponde a guarda temporária dos recipientes contendo os resíduos já acondicionados em local próximo aos pontos de geração, visando, assim, agilizar a coleta dentro do estabelecimento e otimizar o deslocamento entre os pontos geradores e o ponto destinado à apresentação para coleta externa. A RDC ressalta ainda que não poderá ser feito armazenamento temporário com disposição direta dos sacos sobre o piso, sendo obrigatória a conservação dos sacos em recipientes de acondicionamento.

\subsection{Tratamento}

O tratamento consiste na aplicação de método, técnica ou processo de modificação das características dos riscos inerentes aos resíduos, reduzindo ou eliminando o risco de contaminação, de acidentes ocupacionais ou de dano ao meio ambiente. O tratamento pode ser realizado no próprio estabelecimento gerador, ou em outro estabelecimento, observadas nestes casos, as condições de segurança para o transporte entre o estabelecimento gerador e o local do tratamento (RDC ANVISA $\left.n^{\circ} .306,2004\right)$.

\subsection{Armazenamento externo}

O armazenamento externo consiste na guarda dos recipientes de resíduos até a realização da etapa de coleta externa, em ambiente exclusivo com acesso facilitado aos veículos coletores (RDC ANVISA $n^{\circ}$. 306, 2004).

\subsection{Coleta e transporte externos}

De acordo com a RDC da ANVISA, $n^{\circ} .306$ (2004), as etapas de coleta e transporte externos consistem na remoção dos RSS do local de armazenamento externo até a unidade de tratamento ou disposição final, em que se utilizem técnicas que garantam a preservação das condições de acondicionamento e a integridade dos trabalhadores, da população e do meio ambiente, de acordo com as orientações dos órgãos de limpeza urbana. A RDC ainda coloca que a coleta e transporte externos dos resíduos de serviços de saúde devem ser realizados de acordo com as normas NBR 12810 e NBR 14652 da ABNT.

\subsection{Disposição final}

Segundo a resolução do CONAMA, n. 358/2005, a disposição final de resíduos de serviços de saúde consiste na prática de dispor os resíduos sólidos no solo previamente preparado para recebê-los, de acordo com critérios técnico-construtivos e operacionais adequados, em consonância com as exigências dos órgãos ambientais competentes.

Conforme o Manual de Saneamento, elaborado pela Fundação Nacional de Saúde (FUNASA, 2006), a disposição final adequada dos resíduos hospitalares deve ser realizada em aterro controlado ou sanitário, 
que será implantada (dependendo do caso), pelo projeto técnico que siga rigorosamente a Norma da Associação Brasileira de Normas Técnicas, o qual determina os métodos e processos de apresentação de projetos tanto de aterros controlados como de aterros sanitários de resíduos sólidos urbanos.

\section{MÉTODO DO ESTUDO}

O presente estudo caracteriza-se, quanto à abordagem, como qualitativo. Conforme Richardson (1999), geralmente as investigações que se voltam para uma análise qualitativa têm como objeto situações complexas ou estritamente particulares, como é o caso do gerenciamento de resíduos do serviço de saúde em um hospital universitário. Dessa forma, a presente pesquisa é de caráter exploratório, já que pretende explorar esta temática. Corroborando Gil (2007), enfatiza que a pesquisa exploratória tem por finalidade ampliar o conhecimento a respeito de determinado fenômeno, explorando uma determinada realidade.

Para o desenvolvimento da pesquisa utilizou-se o método de estudo de caso. Para Yin (2001), o estudo de caso é uma estratégia de pesquisa empírica que investiga um fenômeno contemporâneo dentro de um contexto da vida real, quando a fronteira entre o fenômeno e o contexto não é claramente evidente e onde múltiplas fontes de evidência são utilizadas. Dessa forma, este estudo buscou analisar gerenciamento dos RSS em um hospital universitário, localizado no estado do Rio Grande do Sul.

\subsection{Unidade de análise}

O hospital objeto desta pesquisa, denominado para fins deste estudo como Hospital Alpha, caracteriza-se por ser uma instituição beneficente, de médio porte, localizada no interior do estado do Rio Grande do Sul, possui em média duzentos e vinte (220) leitos e oitocentos (800) colaboradores.

\subsection{Coleta de Dados}

A coleta de dados foi realizada por meio de observação direta, a partir de visita ao hospital analisado e entrevista semi-estruturada com o Engenheiro de Segurança do Trabalho, responsável técnico pelo gerenciamento de resíduos do hospital analisado.

Os dados foram coletados a partir da adaptação dos modelos propostos por Oliveira (2002) e Lippel (2003), e buscou identificar no Hospital Alpha os aspectos relacionados no Quadro 1.

\section{Quadro 1-Aspectos a serem identificados no estudo}

\begin{tabular}{|c|l|}
\hline & ASPECTOS ANALISADOS \\
\hline$\checkmark$ & Aspectos gerais \\
\hline$\checkmark$ & Geração e minimização de resíduos \\
\hline$\checkmark$ & Acondicionamento e armazenamento \\
\hline$\checkmark$ & Coleta e transporte interno \\
\hline$\checkmark$ & Armazenamento final \\
\hline$\checkmark$ & Tratamento e destino final \\
\hline
\end{tabular}

Fonte: Adaptado a partir de Oliveira (2002) e Lippel (2003)

\subsection{Análise e Interpretação dos Dados}

Os critérios para a interpretação dos dados referem-se à análise das evidências. Para o estudo de caso, Yin (2001) destaca que o objetivo final da análise é o de tratar as evidências de forma adequada para se obter conclusões analíticas convincentes e eliminar interpretações alternativas. Assim, os dados serão interpretados com base nos pressupostos teóricos, comparando os dados empíricos com padrões previstos, apresentados de acordo com as categorias evidenciadas no Quadro 1. 


\section{APRESENTAÇÃO E DISCUSSÃO DOS RESULTADOS}

Os resultados serão apresentados de acordo com os seguintes critérios: Aspectos gerais, Geração e minimização de resíduos, Acondicionamento e armazenamento, Coleta e transporte interno, Armazenamento final, Tratamento e destino final.

\subsection{Aspectos gerais}

\subsubsection{Plano de Gerenciamento de Resíduos do Serviço de Saúde - PGRSS}

Com relação ao gerenciamento dos RSS, convém ressaltar que, desde 2003, o Hospital Alpha implantou o Plano de Gerenciamento de Resíduos do Serviço de Saúde - PGRSS, de acordo com as exigências da legislação do Conselho Nacional do Meio Ambiente (CONAMA) para serviços de saúde, bem como com a legislação federal definida pela ANVISA. Segundo as Resoluções RDC 306/2004 e CONAMA 358/2005, todo o gerador de RSS deve elaborar um PGRSS, baseado nas características dos resíduos gerados e na classificação existente, estabelecendo as diretrizes de manejo dos RSS. O fato de o Hospital Alpha possuir o PGRSS, desde 2003, demonstra a significativa preocupação deste estabelecimento com relação à questão ambiental através do gerenciamento adequado dos RSS.

\subsubsection{Gerenciamento de Resíduos do Serviço de Saúde no Hospital Alpha}

Segundo o Engenheiro de Segurança do Trabalho, de modo geral, o gerenciamento dos resíduos no hospital analisado compreende as seguintes etapas:

- Inicialmente, os resíduos são recolhidos das lixeiras pelos colaboradores do setor de Higienização e armazenados nos pontos de armazenamento temporário, os quais existem em cada setor (andar) do hospital;

- Posteriormente, os resíduos são recolhidos por profissionais que cuidam especificamente desta questão. O recolhimento é feito por meio de carrinhos com tampa, sendo que cada tipo de resíduo (biológico, orgânico ou químico) é recolhido em recipientes específicos, identificados através de cores diferentes, de acordo com o tipo de resíduo;

- Na seqüência, os sacos de resíduos são depositados em um local de armazenamento externo, de onde são recolhidos pelas empresas responsáveis. Os resíduos orgânicos são armazenados em sacos pretos e recolhidos pela Prefeitura do município, já os resíduos biológicos e químicos são armazenados em sacos brancos e "descartex" e são recolhidos por uma empresa especializada, a qual é responsável pelo destino final (autoclavagem) de tais resíduos. Quanto aos resíduos secos recicláveis, como papelão e embalagens plásticas, são encaminhados para doação.

- Os resíduos do Centro Cirúrgico são recolhidos por intermédio de um monta-carga que consiste em um equipamento para transporte vertical, ou seja, os sacos são colocados no monta-carga pelos profissionais do Centro Cirúrgico e, após, recolhidos pelos responsáveis pela coleta de resíduos.

\subsubsection{Colaboradores envolvidos diretamente no Gerenciamento de RSS do Hospital Alpha}

Com relação aos recursos humanos envolvidos diretamente no gerenciamento dos resíduos do Hospital Alpha, o estabelecimento possui dois funcionários, um em cada turno, além de um colaborador para trabalhar nos dias de folga dos demais.

O entrevistado enfatiza que todos os funcionários envolvidos no gerenciamento de resíduos utilizam equipamentos de proteção individual, tais como: luvas de látex, máscara e óculos de proteção. Conforme observado, este critério não está totalmente de acordo com a legislação, visto que a NBR 12810 da ABNT (1993) ressalta que o uniforme deve ser composto por calça comprida e camisa com manga, no mínimo de 3/4, de tecido resistente e de cor clara, específico para o uso do funcionário do serviço, de forma a identificá-lo de acordo com a sua função; devem ainda utilizar luvas, botas, gorro, máscara, óculos e avental.

Quanto à capacitação dos funcionários, constatou-se na entrevista, que é de responsabilidade dos colaboradores e da chefia.

Entretanto, cabe ressaltar, o fato do Engenheiro ter enfatizado que o hospital não possui nenhum tipo de treinamento específico acerca da coleta seletiva dos RSS que envolva todos os funcionários do Hospital Alpha. 
Fato este, o qual pode acarretar em problemas para o estabelecimento, uma vez que a conscientização de todos os funcionários para o descarte dos resíduos de forma adequada consiste em fator fundamental para o gerenciamento eficaz dos RSS. Salienta-se que, na visão de Monteiro et. al. (2001), o procedimento mais importante no manuseio de resíduos de serviços de saúde consiste na separação na origem do lixo infectante dos resíduos comuns, sendo que a separação adequada depende, na maioria das vezes, da conscientização dos colaboradores em descartar os resíduos corretamente.

Em caso de acidente de trabalho com a manipulação dos resíduos, o procedimento adotado consiste em, primeiramente, encaminhar o funcionário acidentado para a Comissão de Controle de Infecção Hospitalar $(\mathrm{CClH})$, que o orientará a realizar exames sanguíneos, bem como quanto à medicação profilática a ser administrada. Após, o colaborador é encaminhado à Segurança do Trabalho, que além de registrar, também investigará as causas do acidente.

\subsection{Geração e minimização de resíduos}

Quanto aos aspectos de geração e minimização dos resíduos, o hospital afirma praticar a separação dos resíduos sólidos no estabelecimento através de recipiente específico para cada tipo de resíduo, identificando os resíduos conforme suas características e potencial infectante. A segregação dos RSS no hospital analisado é feita de acordo com a norma de classificação da ANVISA RDC n 306/2004.

\subsection{Acondicionamento e armazenamento}

Em relação ao acondicionamento e armazenamento, o hospital analisado afirma utilizar embalagens de plástico e papel para o armazenamento dos resíduos, seguindo uma padronização de cores, conforme o tipo de resíduos sólidos, o que corrobora com a RDC ANVISA nº. 306/2004. Já o acondicionamento dos resíduos perfuro-cortantes é feito em recipientes descartáveis de papel (descartex), todos dispostos em suportes individuais. Os demais resíduos infectantes são acondicionados em recipientes de plástico com tampa, em sacos brancos. Observou-se que o hospital possui lixeiras com tampas feitas de plástico resistente para o armazenamento dos resíduos, identificadas devidamente, de acordo com o tipo de resíduo, conforme Figura 1.

\section{Figura 1 - Recipientes específicos para separação dos resíduos sólidos}

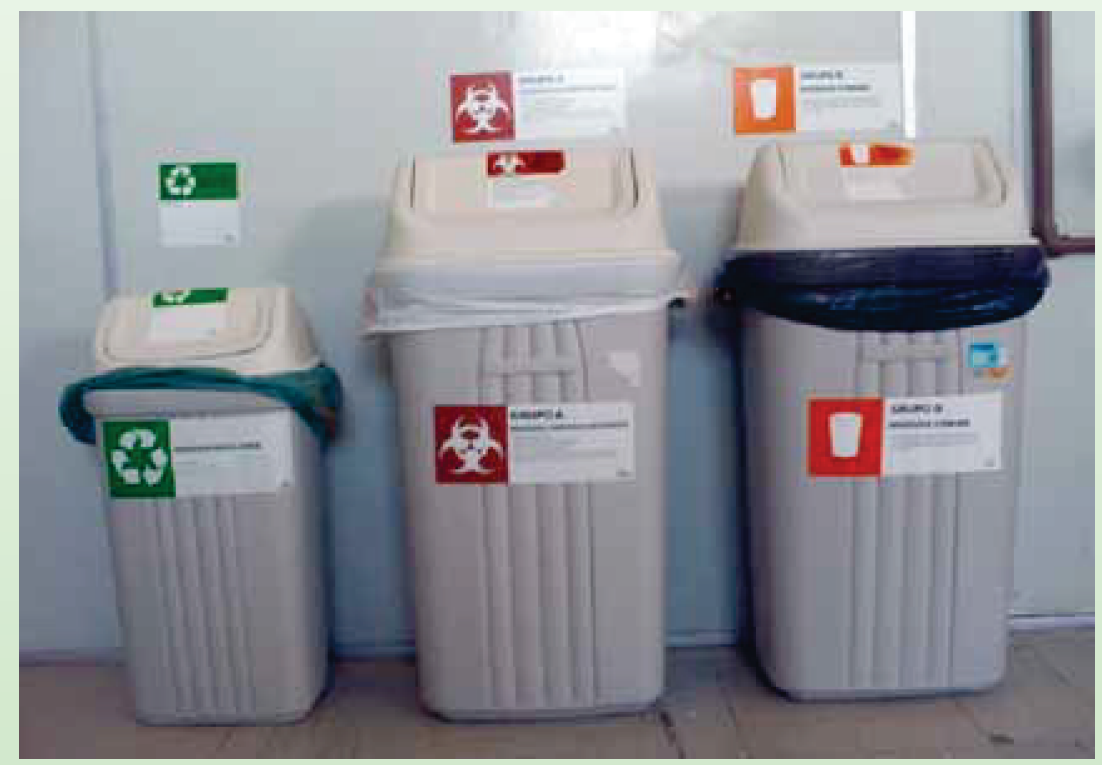

Fonte: Dados da pesquisa

\subsection{Coleta e transporte interno}

A coleta e o transporte interno dos resíduos sólidos são realizados por meio de recipientes de plásticos (carrinhos) com tampa e rodas, com capacidade para duzentos e cinqüenta (250) litros, sendo específicos para cada tipo de resíduo, conforme Figura 2. As características dos carros utilizados para transporte interno confirmam o que foi ressaltado por Cussiol (2008), quanto aponta que o carro ou recipiente utilizado para o transporte interno dos resíduos deve ser de uso exclusivo e específico para cada grupo de resíduo, sendo constituído de material rígido, lavável, impermeável, provido de tampa articulada ao próprio 
corpo do equipamento, com cantos e bordas arredondados e identificados com o símbolo correspondente ao risco do resíduo que transportará.

O engenheiro destaca que os recipientes são higienizados diariamente, utilizando-se água, por meio de mangueira, e hipoclorito. Constatou-se que a coleta é feita diariamente, uma vez por turno, com base em roteiro previamente definido e em horários que não coincidem com a distribuição de roupas, alimentos e medicamentos, horários de visita ou de maior fluxo de pessoas e atividades; sendo que o fluxo do transporte interno é feito de cima para baixo, isto é, inicia-se a coleta a partir dos andares mais elevados até o térreo. Tais características estão de acordo com o disposto na RDC ANVISA nº. 306 (2004).

\section{Figura 2 - Carrinhos específicos para cada tipo de resíduo}

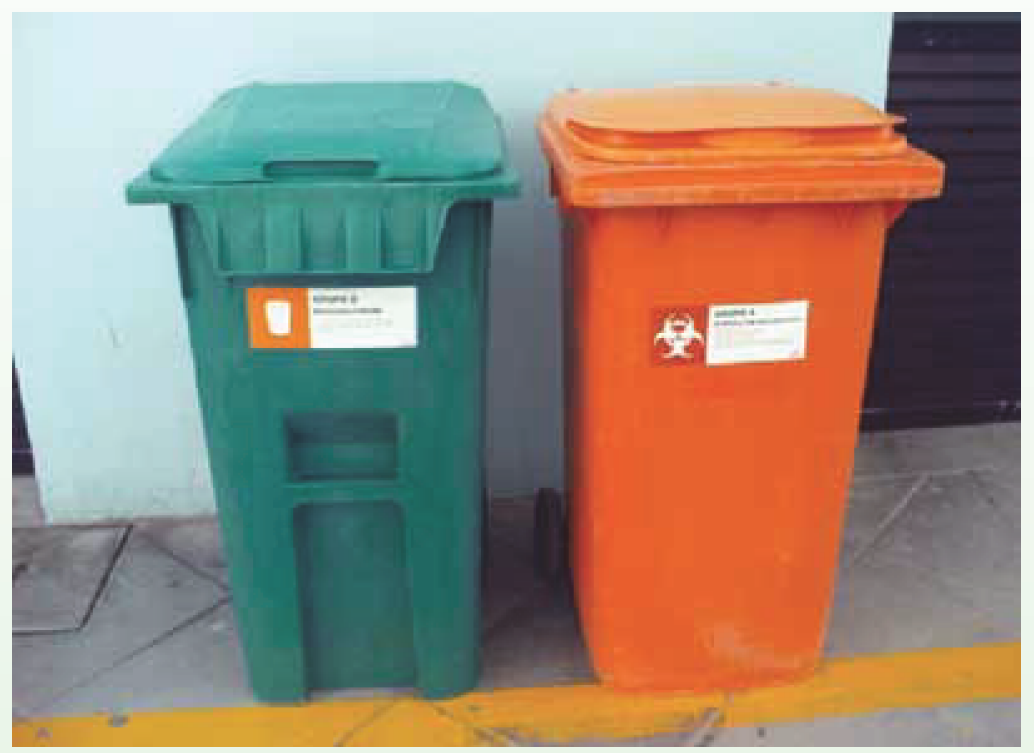

Fonte: Dados da pesquisa

\subsection{Armazenamento final}

Constatou-se que no Hospital Alpha os resíduos são armazenados em local específico para seu posterior destino final, conforme Figura 3. Este local trata-se de um depósito de armazenamento externo, localizado externamente ao hospital e de fácil acesso aos responsáveis pela coleta urbana, características estas que estão de acordo com o estabelecido na RDC ANVISA n 306/04. Este local é construído em alvenaria, com porta e janelas de alumínio e revestido internamente (piso e paredes até o teto) com material lavável (cerâmica).

Figura 3 - Depósito de armazenamento externo

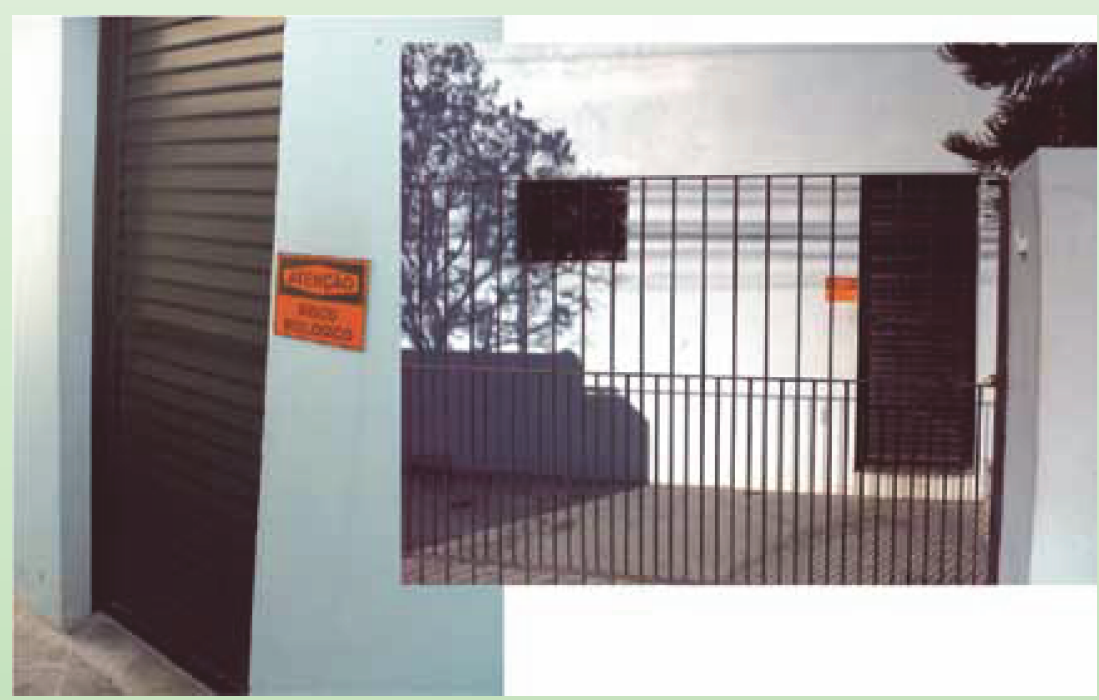

Fonte: Dados da pesquisa 


\subsection{Tratamento e destino final}

Por fim, quanto ao tratamento e à destinação final dos resíduos gerados no estabelecimento, o Engenheiro afirma que os resíduos orgânicos são recolhidos pela Prefeitura e depositados em aterro sanitário, enquanto que os resíduos infectantes (biológicos e químicos) são recolhidos e autoclavados por empresa especializada. Ao estar de acordo com legislação, uma vez que a RDC ANVISA, $n^{\circ}$. 306/2004, coloca que o tratamento pode ser aplicado no próprio estabelecimento gerador ou em outro estabelecimento, observa-se, nestes casos, as condições de segurança para o transporte entre o estabelecimento gerador e o local do tratamento.

As principais características evidenciadas neste estudo com relação ao gerenciamento de RSS no Hospital Alpha serão apresentadas no Quadro 2.

Quadro 2 - Principais características do gerenciamento de RSS no Hospital Alpha

\begin{tabular}{|c|c|}
\hline \multicolumn{2}{|c|}{ Gerenciamento de RSS no Hospital Alpha } \\
\hline $\begin{array}{l}\text { Plano de Gerenciamento } \\
\text { de Resíduos do Serviço de } \\
\text { Saúde - PGRSS }\end{array}$ & $\begin{array}{l}\text { - Implantado desde } 2003 \text { de acordo com as exigências } \\
\text { da legislação do Conselho Nacional do Meio Ambiente } \\
\text { (CONAMA) para serviços de saúde, bem como com a } \\
\text { legislação federal definida pela ANVISA. }\end{array}$ \\
\hline Segregação & $\begin{array}{l}\text { - Os resíduos sólidos são separados através de recipiente } \\
\text { específico para cada tipo de resíduo, identificando os resíduos } \\
\text { conforme suas características e potencial infectante. }\end{array}$ \\
\hline $\begin{array}{l}\text { Acondicionamento } \\
\text { armazenamento }\end{array}$ & $\begin{array}{l}\text { - Os resíduos são armazenados em embalagens de plástico } \\
\text { e papel seguindo uma padronização de cores, conforme o } \\
\text { tipo de resíduo sólido, de acordo com a legislação vigente; } \\
\text { - O hospital possui lixeiras com tampas feitas de plástico } \\
\text { resistente, para o armazenamento dos resíduos, } \\
\text { identificadas devidamente de acordo com o tipo de resíduo. }\end{array}$ \\
\hline Coleta e transporte interno & $\begin{array}{l}\text { - Osresíduossãorecolhidosdosrecipientesdearmazenamento } \\
\text { pelos colaboradores do setor de Higienização e colocados } \\
\text { em local de armazenamento temporário, existentes em } \\
\text { cada setor (andar) do hospital; } \\
\text { - Os resíduos são recolhidos por profissionais que cuidam } \\
\text { especificamente desta questão, por meio de carrinhos } \\
\text { com tampa; } \\
\text { - Cada tipo de resíduo (biológico, orgânico ou químico) é } \\
\text { recolhido em recipientes específicos, identificados através } \\
\text { de cores diferentes, de acordo com o tipo de resíduo. }\end{array}$ \\
\hline Armazenamento Final & $\begin{array}{l}\text { - Os resíduos são armazenados em um depósito de } \\
\text { armazenamento externo para seu posterior destino final. } \\
\text { Este local está localizado externamente ao hospital e é de } \\
\text { fácil acesso aos responsáveis pela coleta urbana, o mesmo } \\
\text { é construído em alvenaria, com porta e janelas de alumínio } \\
\text { e revestido internamente (piso e paredes até o teto) com } \\
\text { material lavável (cerâmica). }\end{array}$ \\
\hline Tratamento e destino final & $\begin{array}{l}\text { - Os resíduos orgânicos são recolhidos pela prefeitura e } \\
\text { depositados em aterro sanitário; } \\
\text { - Os resíduos infectantes (biológicos e químicos) são } \\
\text { recolhidos e autoclavados por empresa especializada. } \\
\text { - Os resíduos secos recicláveis, como papelão e embalagens } \\
\text { plásticas, são doados. }\end{array}$ \\
\hline
\end{tabular}

Fonte: Dados da pesquisa 


\section{CONSIDERAÇÕES FINAIS}

Ao estabelecer como objetivo deste estudo analisar o gerenciamento dos RSS em um hospital universitário, localizado no estado do Rio Grande do Sul, foi possível evidenciar a significativa preocupação do Hospital Alpha com o gerenciamento adequado dos RSS, destacando-se a implantação, desde 2003, do Plano de Gerenciamento de Resíduos do Serviço de Saúde - PGRSS, que normatiza e descreve as etapas de segregação, manejo e descarte dos resíduos hospitalares, a fim de que se minimizem os riscos à saúde.

Constatou-se que a maioria das questões analisadas está de acordo com a legislação vigente, o que demonstra que o Hospital Alpha já despertou para esta questão tão complexa e importante, já que o gerenciamento dos RSS trata-se de um assunto polêmico e amplamente discutido, tendo em vista que a manipulação inadequada destes resíduos pode representar grandes riscos e problemas ao meio ambiente e à saúde humana.

Identificou-se uma lacuna com relação a treinamentos promovidos pelo hospital no que se refere a esta temática. Neste sentido, sugere-se ao Hospital Alpha uma maior atenção quanto ao fato de não possuir nenhum tipo de treinamento específico referente à coleta seletiva dos RSS, que envolva todos os funcionários. Fato este, que pode acarretar em problemas para o estabelecimento, uma vez que a conscientização de todos os funcionários para o descarte dos resíduos de forma adequada consiste em fator fundamental para o gerenciamento eficaz dos RSS. Faz-se necessária ainda uma adequação quanto aos Equipamentos de Proteção Individual, já que se constatou que os colaboradores não utilizam todos aqueles previstos na legislação.

Por fim, ressalta-se que o objetivo fundamental do gerenciamento dos resíduos sólidos consiste em reduzir os riscos para a saúde da população interna e externa do estabelecimento de saúde, sendo importante para garantir a qualidade da saúde coletiva e a preservação do meio ambiente (CUSSIOL, 2008; MOURA E VIRIATO, 2008).

Dessa feita, enfatiza-se a importância da preocupação ambiental por parte das organizações de saúde, principalmente no que se refere ao gerenciamento adequado dos RSS, tendo em vista que ao prestarem assistência para a população, torna-se imprescindível a segurança nos serviços prestados, já que qualquer ação indevida pode acarretar danos para os pacientes, profissionais da área da saúde e comunidade em geral.

\section{REFERÊNCIAS}

ABNT - ASSOCIAÇÃO BRASILEIRA DE NORMAS TÉCNICAS. NBR 12807. Rio de Janeiro: ABNT, 1993 ABNT - ASSOCIAÇÃO BRASILEIRA DE NORMAS TÉCNICAS. NBR 12810. Rio de Janeiro: ABNT, 1993 ABNT - ASSOCIAÇÃO BRASILEIRA DE NORMAS TÉCNICAS. NBR 10004. Rio de Janeiro: ABNT, 2004 AGÊNCIA NACIONAL DE VIGILÂNCIA SANITÁRIA - ANVISA (Brasil). Resolução da Diretoria Colegiada - RDC n. 306, de 07 de dezembro de 2004. Dispõe sobre o Regulamento Técnico para o gerenciamento de resíduos de serviços de saúde. Diário Oficial da União, 10 dez. 2004.

ALMEIDA, R. de A. Jr.; AMARAL, S. P. Lixo urbano, um velho problema atual. In: SIMPEP, 13, 2006, São Paulo. Anais. São Paulo: UNESP, 2006.

CARRAMENHA, M. M. L. Gerenciamento de resíduos sólidos em serviços de saúde: uma contribuição para a avaliação do desempenho ambiental. Dissertação (Mestrado em Engenharia Ambiental Urbana) - Escola Politécnica da Universidade Federal da Bahia, Salvador, 2005.

COELHO H. Manual de gerenciamento de resíduos sólidos de serviços de saúde. Rio de Janeiro: FIOCRUZ; 2001.

CONSELHO NACIONAL DO MEIO AMBIENTE - CONAMA (Brasil). RESOLUÇÃO CONAMA n. 358 , de 29 de abril de 2005. Dispõe sobre o tratamento e a disposição final dos residuos dos serviços de saúde e dá outras providências. Diário Oficial da União, 04 maio 2005.

CUSSIOL, N. A. de M. Manual de gerenciamento de resíduos de serviços de saúde. Belo Horizonte: Fundação Estadual do Meio Ambiente - FEAM, 2008.

FUNDAÇÃO NACIONAL DE SÁUDE - FUNASA (Brasil). Manual de Saneamento. 3 ed. rev. Brasília: Fundação Nacional de Saúde, 2006.

GIL, A. C. Métodos e técnicas de pesquisa social. São Paulo: Atlas, 2007. 
LIPPEL, M. Modelo de gerenciamento de resíduos sólidos de saúde para pequenos geradores - o caso de Blumenau/SC. Dissertação (Mestrado em Engenharia de Produção) - Universidade Federal de Santa Catarina, Florianópolis, 2003.

MONTEIRO, J.H.P. et. al. Manual de Gerenciamento Integrado de resíduos sólidos. Coordenação técnica Victor Zular Zveibil. Rio de Janeiro: IBAM, 2001.

MOURA, A. de, VIRIATO, A. Gestão Hospitalar. São Paulo: Manole, 2008.

NAIME, R.; RAMALHO, A. H. P.; NAIME, I. S. Avaliação do sistema de gestão dos resíduos sólidos do Hospital de Clínicas de Porto Alegre. Revista Espaço para a Saúde, Londrina, v.9, n.1, p.1-17, dez. 2008.

OLIVEIRA, J. M. de. Análise do Gerenciamento de Resíduos de Serviços de Saúde nos Hospitais de Porto Alegre. Dissertação (Mestrado em Administração) - Universidade Federal do Rio Grande do Sul, Porto Alegre, 2002.

ORGANIZAÇÃO PAN-AMERICANA DE SAÚDE. Guia para o manejo interno de resíduos sólidos em estabelecimentos de saúde. Tradução de Carol Castillo Argüello. Brasília: Organização PanAmericana da Saúde, 1997.

RICHARDSON, R. J. Pesquisa Social: métodos e técnicas. 1999. São Paulo: Atlas.

YIN, R. K. Estudo de caso: planejamento e métodos. 2 ed. Porto Alegre: Bookman, 2001. 